\title{
Role of Community Medicine Experts in the Changing Epidemiological Context of Nepal
}

Pranil Man Singh Pradhan ${ }^{1,2^{*}}$

${ }^{1}$ Department of Community Medicine, Maharajgunj Medical Campus, Institute of Medicine, Tribhuvan University

${ }^{2}$ Nepalese Society of Community Medicine (NESCOM)

Received:

22 May 2020

Revised:

16 April 2021

Accepted:

8 May 2021

*Corresponding

author

pranil.pradhan@

gmail.com

\begin{abstract}
Community Medicine experts are a valuable resource for a stronger health care system in Nepal. They have made significant contributions to the health sector yet have remained largely under-utilized in the national health care system. The health system is likely to be restructured considering the current COVID-19 pandemic and this is the right opportunity to utilize this pool of experts at different levels of the health system.
\end{abstract}

Keywords: Community Medicine, COVID-19, Nepal

Tweetable abstract: Community Medicine experts remain an under-utilized human resource in the Nepalese health system.

\section{Introduction}

Community Medicine is a specialized branch of medical science aiming to promote health, prevent diseases, and prolong life through a range of interventions (promotive, preventive, curative, rehabilitative, and palliative) in close partnership with the health care delivery system, active community participation, and intersectoral coordination [1]. It includes epidemiology, health care delivery system including primary health care and basic clinical sciences as core subjects. Biostatistics, demography, public health nutrition, social, behavioral, environmental, and management sciences are other critical allied sciences. There are clinical subspecialties of Community Medicine like Community Ophthalmology, Preventive Oncology, Preventive Cardiology, Social/community Pediatrics, and Social/community Obstetrics which are well developed elsewhere [2]. It is a multidisciplinary field with subspecialties like health management, health promotion, research methods, health economics, and occupational and environmental health which add to the core strength of Community Medicine. Experts of Community Medicine can serve as leaders in health care delivery systems, voluntary or development agencies, and as health consultants and health managers at local, federal, national, international, and global levels [1].

Historically the definition of Community Medicine originated from different parts of the world with many similarities. Community Medicine was considered as a group or cooperative medicine in the United States in 1920, to increase access to care and promote equity [3]. The concept of Community Medicine started in South Africa in the 1940s to incorporate family medicine into preventive and social medicine to deliver primary health care [4]. In the United Kingdom, the role of Community Medicine was defined in the 1970s as organizing health and allied services to the community, using the tools of epidemiology and biostatistics to set priorities, and addressing social determinants of health [5]. In India, the concept of preventive and social medicine was started after the recommendation of the Joseph Bhore Committee in 1946 with the aim of training doctors who not only provide clinical care but also engage with the community to solve their health needs [5].

\section{Historical development and current context of Community Medicine in Nepal}

Community Medicine education in Nepal began with the establishment of Maharajgunj Medical Campus in Tribhuvan University in 1972, with the Department of Community Medicine as one of the first departments. With the mandate from the Government of Nepal to develop public health workforce for the country, the department started public health programs in 1987. However, it has not started the post-graduation program on Community Medicine specialty (Doctor of Medicine) yet. Post-graduation in Community Medicine (MD) began from the Department of Community Medicine at B.P. Koirala Institute of Health Sciences, Dharan in 1999 under the guidance of faculties from India. Kathmandu University began post-graduate training in Community Medicine after a decade in 2009. At present, more than 80 graduates of Community Medicine from Nepal and abroad are serving in different health sectors and nearly 40 residents are undergoing residency training. With growing interest in this field, the number of aspirants choosing Community Medicine for specialization is increasing every year in Nepal [6].

The majority of Community Medicine graduates of Nepal are working in academics (69\%) and nearly one-fourth of them are con-

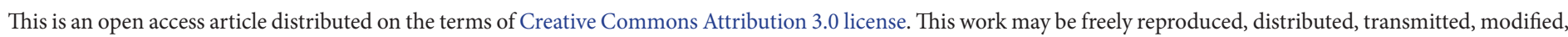
or otherwise used provided that the original work is properly cited. Author emails are available at the end of the article. 
tributing to the development sector as consultants [6]. However, they are largely underutilized in the national health care system. Due to the lack of vacancies, there are fewer opportunities for the graduates to contribute even to academia. Since 2019, some of the graduates have started to serve the government under the Ministry of Health and Population scholarship bond but there is no permanent position in the national health care delivery system yet. Overall, Community Medicine graduates have been collaborating with the public health sector and contributing to national health programs as technical experts for outbreak investigation and response, verbal autopsy, mass casualty management plan, occupational health and safety, hospital preparedness for emergencies (HOPE), and the package of essential non-communicable diseases (PEN), among other sectors.

\section{Role in COVID-19 pandemic}

The ongoing pandemic of severe acute respiratory syndrome coronavirus 2 (SARS-CoV-2) has created an opportunity to utilize Community Medicine graduates in the national health system. They successfully coordinated with the Epidemiology and Disease Control Division (EDCD) and National Health Training Center of the Ministry of Health and Population and provided technical support for rapid assessment, case investigation, and contact tracing at provincial and local levels in the first wave of COVID-19 pandemic in Nepal. Their contribution was significant in developing training materials for case investigation and contact tracing $[7,8]$. They were also given the responsibility of supervising the quarantine spots where people suspected of having SARS-CoV-2 infection were kept [9]. The COVID-19 pandemic is likely to put more emphasis on data, research, and epidemiological surveillance with more investment in preventive medicine therefore Community Medicine graduates, with robust training in epidemiology and research methods, are best suited to accomplish this responsibility [10].

\section{Future prospects}

The priority of the government has now shifted to the restructuring of the health sector in light of the ongoing COVID-19 pandemic [11]. A significant change proposed is the establishment of a National Center for Disease Control which will play a vital role in disease control and prevention [12]. Infectious and communicable disease hospitals will be established in every province [13]. These could be an appropriate platform for Community Medicine graduates to serve the country. The Government of Nepal needs to provide the Community Medicine graduates with permanent placements under the national health service and leverage the opportunities associated with the current federal structure to mobilize them to appropriate positions at provincial and local levels. The academic institutions need to update the curriculum of the MD program according to the current context and institutions not having this program need to begin the homework soon. National Medical Education Regulations under the National Medical Education Act of 2075 has duly recognized Community Medicine as one of the specialty disciplines in Nepal [14].

\section{Conclusion}

Community Medicine is a unique discipline for Nepal even though it shares many similarities with public health. In fact, Community Medicine can be considered as a successor to public health which bridges the gap between public health and clinical medicine, and Community Medicine graduates cum physicians can contribute in areas that promote the synergy between the two disciplines [11]. Graduates of Community Medicine are trained with a public health approach and need to be utilized more by the government sector. This will pave the way for more post-graduate (PG) aspirants to pursue this discipline and contribute towards universal health coverage.

\section{References}

1. Joseph A, Kadri AM, Krishnan A, Garg BS, Ahmed FU, Kumar P, et al. IAPSM Declaration 2018: Definition, Role, Scope of Community Medicine and Functions of Community Medicine Specialists. Indian J community Med Off Publ Indian Assoc Prev Soc Med. 2018;43(2):120-1.

2. Patro B, Singh A. Community medicine departments and public health education in India at crossroads! Indian J Public Heal. 2011;55(1):56-7.

3. Meyer EC. Community Medicine and Public Health. Am J Public Health (N Y). 1920 Jun;10(6):489-97.

4. Shewade H, Jeyashree K, Chinnakali P. Reviving community medicine in India: The need to perform our primary role. Int J Med Public Heal. 2014;4(1):29.

5. Krishnan A. Community Medicine in India - Which Way Forward? Indian J community Med Off Publ Indian Assoc Prev Soc Med. 2016;41(1):5-10.

6. Pradhan P. Update of Status of MD Community Medicine in Nepal [Internet]. 2020 [cited 2020 May 13]. Available from: https://www.researchgate.net/publica-

tion/341355792_Update_of_Status_of_MD_Community_Medicine_in_Nepal

7. Government of Nepal Ministry of Health and Population. Health Sector Response to Coronavirus Disease (COVID-19) [Internet]. Situation Report 70. 2020 [cited 2021 Apr 9]. Available from: https://drive.google.com/drive/folders/1y311GlQGoH5JIQfEeaBmkSKo_prMrZP5

8. Government of Nepal Ministry of Health and Population National Health Training Centre. Case Investigation and Contact Tracing Training Facilitator Guide [Internet]. Kathmandu; 2020. Available from: https://nhtc.gov.np/images/CICT_Facilitators_guide_revised_new.pdf

9. Government of Nepal Ministry of Federal Affairs and General Administration. Quarantine Operation and Management Protocol 2076 [Internet]. [cited 2020 May 14]. Available from: https://www.mofaga.gov.np/news-notice/1803

10. Igoe M, Chadwick V. After the pandemic: How will COVID-19 transform global health and development? [Internet]. Devex. 2020 [cited 2020 May 14]. Available from: https://www.devex.com/news/sponsored/after-the-pandemic-how-will-covid-19-transform-global-health-and-development-96936

11. Ghimire B. Health sector gets priority as government unveils its annual plans amid pandemic. The Kathmandu Post [Internet]. 2020; Available from: https://kathmandupost.com/national/2020/05/16/health-sector-gets-priority-as-government-unveils-its-annual-plans-amid-pandemic

12. Subedi M, Subedi P. Lesson from COVID-19: restructuring the current health system and policies in Nepal. Appl Sci Technol Ann. 2020;1(1):183-6. 
13. Sharma B. Provincial Updates for the Health Cluster Meetings [Internet]. [cited 2021 Apr 1]. Available from: https://un.org.np/sites/default/files/doc_internal/2020-09/Gandaki Province HCCM Presentation\%2C 2020-05-07.pdf

14. Government of Nepal Ministry of Education Science and Technology. National Medical Education Regulations 2077 [Internet]. 2077 [cited 2021 Apr 1]. Available from: http://www.mec.gov.np/public/uploads/shares/ActandRegulation/mec_regulation.pdf 